\title{
Measuring health status in the community: a comparison of methods
}

\author{
Paul Kind, Claire M Gudex
}

\begin{abstract}
Study objective - The measurement of health outcomes is central to the evaluation of medical treatment and intervention. It is generally acknowledged that such measurement ought to include an assessment of the impact of health care on the quality of life, as well as its quantity. The Health Measurement Questionnaire (HMQ) was developed as a means of identifying respondents in terms of Rosser's classification of illness states. This study examines the extent of convergent validity of the HMQ when used as a self report measure of health status, alongside the General Health Questionnaire (GHQ) and the Nottingham Health Profile (NHP).
\end{abstract}

Design - A randomised survey of residents of Wolverhampton was drawn from the electoral register. Interviews were conducted in the respondents' own homes. The three measurement instruments formed part of an extensive battery of questionnaires aimed at assessing a broad range of health issues.

Participants - A total of 430 respondents were interviewed, of whom 407 completed the HMQ. Altogether 210 also completed the GHQ, and a further 207 completed the NHP. Failure in the interview protocol meant that 12 respondents did not complete either the GHQ or the NHP; these respondents did complete their HMQ.

Measurements and main results - At the descriptive level, Rosser distress categories derived from the HMQ seem to correlate well with the GHQ. There is a strong association between weighted Rosser disability/distress states and scores produced using the NHP. All three measures discriminated between "healthy" and "not healthy" subgroups of respondents. Conclusions - The results indicate strong evidence for convergent validity. There are significant levels of physical and psychological morbidity within the community. The results of this study reinforce the case for the continued measurement of health status within the general population. Low cost techniques such as the HMQ offer the prospect of such measurement.

Centre for Health Economics, University of York, York YO1 5DD

$P$ Kind

C M Gudex

(f Epidemiol Community Health 1994;48:86-91)

Correspondence to: Mr P Kind.

Accepted for publication August 1993

The measurement of health outcome is central to the evaluation of medical treatment and intervention. In the past, this measurement has tended to emphasise the importance of data on survival and life expectancy. It is now generally acknowledged, however, that a thorough assessment of the benefits of health care must examine the quality of life as well as its quantity. There is a steadily growing number of published reports that describe the application of health status or health related quality of life measures in assessing the benefits of medical care. ${ }^{1-3}$ There are now several "standard" measures from which to choose. Standard, in this context, means simply that the measures have been developed after systematic enquiry, have used accepted methods, and have been used in a wide range of patient groups. ${ }^{45}$

The application of these measures, however, is not restricted to the evaluation of health status in patient groups. Preventive medicine has an increasingly important role and is concerned with the assessment of risk factors, screening for disease, and health education. In doing so, it focuses on the general population, rather than on patients with a particular disease.

There is concern that, for various reasons, there is much ill health in the community that is not being recognised by the health care system. As a result there is increasing interest in describing the health of the general population..$^{6-8}$ Several studies have sought to quantify this health status, either as a series of scores on various health dimensions ${ }^{910}$ or as a single index representing weighted health status. ${ }^{112}$

The Rosser Classification of Illness States was developed in the UK in the 1970s, and has been used as the basis for the measurement of health related quality of life (QoL) in the estimation of quality adjusted life years (QALYs). ${ }^{1314}$ The health states are described in terms of two dimensions - disability (functional status) and distress (covering pain, anxiety, depression, and reaction to illness). In its original form the classification was intended for use by a professional medical observer to rate the health status of a patient in hospital. When surveying the general population, however, a self rated measurement tool is more useful than an observer rated scale. The Health Measurement Questionnaire (HMQ) was developed at the Centre for Health Economics, York as an alternative way of collecting relevant information from which a corresponding Rosser disability/distress rating could be derived. It was first reported in 1988 as part of a paper describing its potential value in calculating QALYs. ${ }^{15}$

Validity is difficult to establish in absolute been defined as "the correlation of one 
measure with another at the same point in time ... If two different measures of the same phenomenon are hypothesised to be highly correlated, and they are, then one can have greater confidence that the health status measure is valid". ${ }^{16}$ We report on the convergent validity of the HMQ, explored as part of a survey of the general population in which it was used as a self report measure of health status, alongside the General Health Questionnaire (GHQ) and the Nottingham Health Profile (NHP).

\section{Method}

As part of a survey carried out in Wolverhampton, ${ }^{17}$ respondents completed a battery of questionnaires aimed at assessing their general health status and health related quality of life. In this study, a random sample of 801 people from the Wolverhampton electoral register were contacted and asked to participate in a study about health and illness. A total of 430 people agreed to be interviewed in their own homes during October and November 1986. At interview, information was collected on health behaviour, life events, self reported medical history, as well as on sociodemographic variables such as employment and marital circumstances. Respondents were asked to complete either the GHQ or the NHP. In addition, the HMQ was included to investigate its validity. The data from these three instruments have been treated as a separate data set and are reported here. A total of

Table 1 Sociodemographic characteristics of the study population compared with the British population*

\begin{tabular}{|c|c|c|}
\hline & $\begin{array}{l}\text { Study population } \\
(n=407)\end{array}$ & Great Britain \\
\hline $\begin{array}{c}\text { Age }(y): \\
15-24 \\
25-44 \\
45-64 \\
65-74 \\
75+\end{array}$ & $\begin{array}{r}11 \cdot 8 \\
34 \cdot 7 \\
33 \cdot 3 \\
13 \cdot 3 \\
6 \cdot 9\end{array}$ & $\begin{array}{r}16 \cdot 7 \\
35 \cdot 9 \\
28 \cdot 2 \\
11 \cdot 5 \\
7 \cdot 7\end{array}$ \\
\hline $\begin{array}{c}\text { Gender: } \\
\text { Male } \\
\text { Female }\end{array}$ & $\begin{array}{l}45 \cdot 1 \\
54 \cdot 7\end{array}$ & $\begin{array}{l}48 \cdot 6 \\
51 \cdot 4\end{array}$ \\
\hline $\begin{array}{l}\text { Socioeconomic group: } \\
\text { I } \\
\text { II } \\
\text { III non-manual } \\
\text { III manual } \\
\text { IV } \\
\text { V } \\
\text { Never worked } \\
\text { Student } \\
\text { Other (housewife, armed forces, } \\
\text { inadequate description) }\end{array}$ & $\begin{array}{r}2 \cdot 5 \\
12 \cdot 8 \\
25 \cdot 6 \\
38 \cdot 2 \\
12 \cdot 8 \\
2 \cdot 2 \\
1 \cdot 7 \\
1 \cdot 2 \\
3 \cdot 0\end{array}$ & $\begin{array}{r}2 \cdot 5 \\
14 \cdot 6 \\
14 \cdot 8 \\
17 \cdot 2 \\
13 \cdot 0 \\
4 \cdot 6 \\
-\quad 4 \cdot 2 \\
29 \cdot 0\end{array}$ \\
\hline $\begin{array}{l}\text { Economic status: } \\
\text { Full time job } \\
\text { Part time job } \\
\text { Seeking work } \\
\text { Sick/disabled } \\
\text { Retired } \\
\text { Keeping house } \\
\text { In education }\end{array}$ & $\begin{array}{r}33 \cdot 3 \\
11 \cdot 1 \\
8 \cdot 6 \\
4 \cdot 7 \\
17 \cdot 7 \\
23 \cdot 2 \\
1 \cdot 2\end{array}$ & $\begin{array}{r}45 \cdot 6 \\
9 \cdot 4 \\
5 \cdot 2 \\
2 \cdot 6 \\
11 \cdot 4 \\
21 \cdot 3 \\
4 \cdot 3\end{array}$ \\
\hline $\begin{array}{l}\text { Buying/bought own house } \\
\text { Own/use of a car }\end{array}$ & $\begin{array}{l}46 \cdot 8 \\
61 \cdot 6\end{array}$ & $\begin{array}{l}59 \cdot 0 \\
62 \cdot 0\end{array}$ \\
\hline $\begin{array}{l}\text { Probable ethnic group: } † \\
\text { White } \\
\text { Asian } \\
\text { Afro-Caribbean } \\
\text { Not seen }\end{array}$ & $\begin{array}{c}85 \cdot 7 \\
11 \cdot 1 \\
2 \cdot 0 \\
0\end{array}$ & $\begin{array}{r}91 \cdot 0 \\
\} \\
3 \cdot 0 \\
5 \cdot 0\end{array}$ \\
\hline
\end{tabular}

* Data for Great Britain are from the 1984 General Household Survey ${ }^{26}$ except for data on socioeconomic status and economic status which come from 1981 census. $^{27}$

All figures are percentages; columns may not add up to $100 \%$ due to missing data.

+ As assessed by interviewer.
210 respondents completed both the GHQ and the HMQ, and 207 completed both the NHP and the HMQ. Data from the remaining respondents were incomplete.

The $\mathrm{GHQ}^{18}$ was designed to be a self administered screening test aimed at detecting psychiatric disorders in respondents in community settings; it therefore focuses on psychological components of ill health. Scores for the GHQ are calculated by counting the number of times a respondent answers "more than usual" or "much more than usual" to 12 questions. Scores can therefore range from 0 to 12. Respondents with a score of 3 or less are considered to be within the normal range, and those with 4 or more are deemed to have a psychiatric problem. The GHQ yields scores which are produced by counting item responses, and these data have therefore been treated as ordinal, and the median has been used as a measure of central tendency.

The $\mathrm{NHP}^{919}$ is a self administered questionnaire which was designed to measure perceived health status and the extent to which health problems affect normal activities. It has been used as a measure of patient outcome in a variety of groups, including heart transplant recipients ${ }^{20}$ and patients with stroke, ${ }^{21}$ Parkinson's disease, ${ }^{22}$ and arthritis. ${ }^{23}$ Part 1 of the NHP consists of 38 "yes/no" questions in six dimensions: physical mobility, energy, pain, sleep, social isolation, and emotional reaction. A weight is applied to each statement and this enables a score (ranging from 0 to 100 ) to be calculated for each dimension independently, for each respondent. The higher the score, the worse the level of functioning.

The Rosser Classification of Illness States ${ }^{1124}$ consists of two dimensions of health (disability and distress) which have eight and four levels of functioning respectively. Each combination of these levels has been valued, to produce a matrix of scores for 29 states (the eighth level of disability - "unconscious" - has only one score). Each number represents the value or "utility" of being in a particular health state, where a score of 1.00 reflects full health (no disability and no distress) and a score of 0.00 represents death. Two states have negative scores, and are considered to be worse than death. The direction of the Rosser score is therefore opposite to that of both the GHQ and the NHP scores.

The HMQ ${ }^{1525}$ has four sections of "yes/no" questions, asking about mobility, self care, usual activities, and social and personal relationships. The fifth section lists a number of "feelings", and asks the respondent to indicate the degree of distress caused by each feeling, using a $10 \mathrm{~cm}$ visual analogue scale. On the basis of these answers, each respondent is categorised into one of the 29 disability/distress states according to an algorithm previously published..$^{25}$ The corresponding score from the original Rosser matrix is then assigned to that respondent. These scores range from 1.00 (best state) to -1.5 (worst state). The final question in the HMQ asks the respondent to rate his/her overall quality of life, again using a $10 \mathrm{~cm}$ visual analogue scale. 
Table 2 Health characteristics and behaviour of study population $(n=407)$

\begin{tabular}{lc}
\hline Characteristic & $(\%)$ \\
\hline Has long-standing illness & 44.5 \\
Is on regular medication & 33.7 \\
Body mass index $(\%)^{*}:$ & $11 \cdot 8$ \\
Underweight <20 & $40 \cdot 5$ \\
Acceptable/normal 20-24 & $42 \cdot 3$ \\
Overweight 25+ & $5 \cdot 4$ \\
Missing variable & 23.6 \\
Plays sport regularly & $29 \cdot 5$ \\
Smoking status: & $29 \cdot 2$ \\
Current smoker $\dagger$ & $41 \cdot 3$ \\
Ex-smoker & \\
Never smoked
\end{tabular}

* Body mass index $=$ weight $(\mathrm{kg})$ divided by height $(\mathrm{m})$ squared. $\dagger$ Data on quantities consumed were collected in the survey but not used in this analysis.

(Copies of the HMQ are available from the authors on request.)

\section{Results}

RESPONSE

Table 1 shows that the respondents were fairly representative of the general population of England and Wales with regard to age and sex distribution. There were more respondents in socioeconomic group III (manual and nonmanual), but fewer categorised as "other". This is probably because women in the study group were classified according to their last job, rather than as "housewife". There were fewer respondents in full time jobs, fewer who owned houses, and more who were assessed by the interviewer as being Asian or Afro-Caribbean.

Table 3 Distribution of respondents according to Rosser disability and distress categories

\begin{tabular}{|c|c|c|c|c|c|}
\hline \multirow{2}{*}{$\begin{array}{l}\text { Rosser } \\
\text { disability } \\
\text { category }\end{array}$} & \multicolumn{5}{|c|}{ Rosser distress category } \\
\hline & $\begin{array}{l}A \\
\text { (none) }\end{array}$ & $\begin{array}{l}B \\
\text { (mild) }\end{array}$ & $\begin{array}{l}C \\
\text { (moderate) }\end{array}$ & $\begin{array}{l}D \\
\text { (severe) }\end{array}$ & Total \\
\hline $\begin{array}{l}\text { I } \\
\text { II } \\
\text { III } \\
\text { IV } \\
\text { V } \\
\text { VI }\end{array}$ & $\begin{array}{r}187 \\
12 \\
10 \\
0 \\
4 \\
0\end{array}$ & $\begin{array}{r}60 \\
13 \\
4 \\
0 \\
3 \\
0\end{array}$ & $\begin{array}{r}30 \\
8 \\
11 \\
3 \\
7 \\
0\end{array}$ & $\begin{array}{r}14 \\
6 \\
7 \\
3 \\
7 \\
1\end{array}$ & $\begin{array}{r}291(74 \cdot 6 \%) \\
39(10.0 \%) \\
32(8 \cdot 2 \%) \\
6(1.5 \%) \\
21(5.4 \%) \\
1(0.3 \%)\end{array}$ \\
\hline Total & $\begin{array}{l}213 \\
(54 \cdot 6 \%)\end{array}$ & $\begin{array}{l}80 \\
(20.5 \%)\end{array}$ & $\begin{array}{l}59 \\
(15 \cdot 1 \%)\end{array}$ & $\begin{array}{l}38 \\
(9 \cdot 7 \%)\end{array}$ & 390 \\
\hline
\end{tabular}

Rows represent levels of disability, $\mathrm{I}=$ no disability, $\mathrm{VI}=$ confined to chair; columns represen levels of distress, $A=$ no distress, $D=$ severe distress. Figures are numbers of respondents, with row and column percentages in brackets. Data from 17 respondents were incomplete and therefore could not be used to derive disability and distress categories.

Table 4 Effect of background variables on Rosser score

\begin{tabular}{|c|c|c|}
\hline Variable & \multicolumn{2}{|c|}{ Rosser scores (mean) } \\
\hline $\begin{array}{l}\text { Age }(15-45 \text { y } v 46+\mathrm{y}) \\
\text { Sex (male } v \text { female) } \\
\text { Ethnic group (white } v \text { non-white) }\end{array}$ & $\begin{array}{l}0.99 \\
0.97 \\
0.98\end{array}$ & $\begin{array}{l}0.97 \\
0.98 \\
0.98\end{array}$ \\
\hline $\begin{array}{l}\text { School leaving age } \\
\text { (compulsory/never to school } v \text { more than } 1 \text { year over compulsory age) }\end{array}$ & 0.98 & $1.00+$ \\
\hline Social class $(\mathrm{I}-\mathrm{III}(\mathrm{NM}) v \mathrm{III}(\mathbf{M})-\mathrm{V})$ & 0.99 & $0.97^{*}$ \\
\hline Buying own home (yes $v$ no) & 0.99 & 0.97 \\
\hline Own/use of car (yes $v$ no) & 0.98 & 0.97 \\
\hline No relations in same house $(0 / 1 \vee 2+)$ & 0.97 & 0.98 \\
\hline Usual activity (sick/disabled/seeking work $v$ all others) & 0.94 & $0.99 \dagger$ \\
\hline Smoking (never $v$ ex/current) & 0.99 & $0.97^{*}$ \\
\hline Regular physical exercise (yes $v$ no) & 0.99 & 0.98 \\
\hline Body mass index $(20-24 v$ under $20 /$ over 24$)$ & 0.99 & $0.97^{*}$ \\
\hline Long standing illness (yes $v$ no) & 0.96 & $0.99 \dagger$ \\
\hline Regular medication (yes $v$ no) & 0.95 & $0.99 \dagger$ \\
\hline Limited by illness in past 2 weeks (yes/no) & 0.95 & 0.99 \\
\hline
\end{tabular}

Analysis used $t$ tests, the left hand column shows how variables were divided into two groups, the right hand column shows the mean Rosser scores and significant results.

* Significant, $\mathrm{p}<0.01$.

$\uparrow$ Significant, $\mathrm{p}<0.001$
Table 2 shows the distribution of the respondents on selected health variables. Forty five per cent of respondents reported long standing illness (compared with $33.4 \%$ from the General Household Survey) ${ }^{26}$ and one third were on regular medication. Less than half of the respondents had a body mass index within the "ideal" range of 20 to 24 . Table 3 shows the distribution of derived Rosser distress and disability categories within the overall Rosser matrix. One quarter of respondents were categorised as having at least some disability on the Rosser classification, while nearly half had at least some distress.

Table 4 shows that Rosser scores were significantly lower for those who left school at or before compulsory school leaving age, or those who were below social class III non-manual. In addition, those who were sick (temporarily or permanently), disabled, or who were seeking employment showed significantly lower scores than those whose usual activities are paid employment, housework, education, or who were retired.

Scores were also significantly lower for many of the health related variables, particularly the health behaviour variables - that is, respondents who were current or ex-smokers, were outside the normal range for body mass index, had long standing illness, or took regular medication.

A subgroup of respondents was identified as being "not healthy" at the time of the interview if:

(1) They were disabled $(n=25)$; or

(2) Their health had caused them to cut down their usual activity over the previous two weeks $(n=75)$; or

(3) They were prevented by temporary sickness from seeking work $(n=0)$; or

(4) They were permanently sick or disabled $(n=19)$; or

(5) They had experienced an undesirable decline in physical ability in the previous three months $(n=50)$.

On this basis 107 respondents, out of the total 407 , were identified as being in a suboptimal state of health (some fulfilled more than one criteria).

CONVERGENT VALIDITY: COMPARISON OF DERIVED ROSSER CATEGORIES AGAINST THE GHQ A total of 124 respondents $(59 \%)$ scored zero on the GHQ, while $26(13 \%)$ scored higher than 3. Table 5 gives the median GHQ scores for each of the Rosser disability and distress categories. As expected, the GHQ score rises as the level of distress worsens, but the relationship with disability is less clear. Table 6 shows the Rosser categories of the 26 respondents with a GHQ score greater than 3 (and thus considered to be "psychiatric cases"). Only one of these respondents was in distress category A (no distress), while 14 others had no disability but some degree of distress. Ten of the $26(38 \%)$ were in the "severe distress" category.

Spearman's rank correlation between the Rosser scores and the GHQ scores was -0.43 
Table 5 Median GHQ score for each Rosser disability and distress* category

\begin{tabular}{|c|c|c|c|}
\hline \multirow[t]{2}{*}{ Derived Rosser category } & \multirow[t]{2}{*}{ No respondents } & \multicolumn{2}{|c|}{ GHQ score } \\
\hline & & Median & $I Q$ range \\
\hline $\begin{array}{l}\text { Disability: } \\
\text { I } \\
\text { II } \\
\text { III } \\
\text { IV } \\
\text { V } \\
\text { VI }\end{array}$ & $\begin{array}{r}162 \\
20 \\
17 \\
4 \\
7 \\
0\end{array}$ & $\begin{array}{l}0.0 \\
0.5 \\
0.0 \\
2.5 \\
2.0 \\
-\end{array}$ & $\begin{array}{l}0-1 \cdot 0 \\
0-2 \cdot 0 \\
0-1 \cdot 5 \\
0-8 \cdot 0 \\
0-8 \cdot 0 \\
-\end{array}$ \\
\hline $\begin{array}{l}\text { Distress: } \\
\text { A (none) } \\
\text { B (mild) } \\
\text { C (moderate) } \\
\text { D (severe) }\end{array}$ & $\begin{array}{r}117 \\
41 \\
25 \\
21\end{array}$ & $\begin{array}{l}0.0 \\
1 \cdot 0 \\
2 \cdot 0 \\
3 \cdot 0\end{array}$ & $\begin{array}{l}0-0 \\
0-2 \cdot 0 \\
0-5 \cdot 5 \\
0.5-8 \cdot 0\end{array}$ \\
\hline
\end{tabular}

* Data on distress were incomplete for six respondents.

Table 6 Distribution on Rosser disability/distress matrix of respondents considered to be "psychiatric cases"

\begin{tabular}{lllll}
\hline Rosser disability & \multicolumn{4}{l}{ Rosser distress category } \\
\cline { 2 - 5 } & A (none) & $B$ (mild) & $C$ (moderate) & D (severe) \\
\hline I & 1 & 5 & 6 & 3 \\
II & - & - & 1 & 2 \\
III & - & - & - & 3 \\
IV & - & 1 & -1 & 1 \\
V & & 1 & & 1 \\
\hline
\end{tabular}

Figures represent numbers of respondents in each combination of disability and distress; incomplete data for one respondent.

Table 7 Distribution of derived disability/distress categories and GHQ scores in two subgroups

\begin{tabular}{|c|c|c|}
\hline Category/score & "Healthy" $(n=283)(\%)$ & “Not healthy" ( $n=107)(\%)$ \\
\hline $\begin{array}{l}\text { Rosser disability: } \\
\text { I } \\
\text { II } \\
\text { III } \\
\text { IV } \\
\text { V } \\
\text { VI }\end{array}$ & $\begin{array}{l}84 \cdot 5 \\
8 \cdot 1 \\
4 \cdot 9 \\
(0 \cdot 4) \\
2 \cdot 1 \\
-\quad\left(x^{2}=62 \cdot 8, d f=5, p<0 .\right.\end{array}$ & $\begin{array}{r}48 \cdot 6 \\
15 \cdot 0 \\
16 \cdot 8 \\
4 \cdot 7 \\
14 \cdot 0 \\
(0 \cdot 9)\end{array}$ \\
\hline $\begin{array}{l}\text { Rosser distress: } \\
\text { A } \\
\text { B } \\
\text { C } \\
\text { D }\end{array}$ & $\begin{array}{r}63 \cdot 3 \\
20 \cdot 5 \\
11 \cdot 0 \\
5 \cdot 3 \\
\left(x^{2}=46 \cdot 9, \mathrm{df}=3, \mathrm{p}<0 .\right.\end{array}$ & $\begin{array}{l}31 \cdot 8 \\
20 \cdot 6 \\
26 \cdot 2 \\
21 \cdot 5\end{array}$ \\
\hline $\begin{array}{l}\text { GHQ score: } \\
\leq 3 \\
>3\end{array}$ & $\begin{array}{l}97 \cdot 9 \\
2 \cdot 1 \\
\qquad\left(x^{2}=31 \cdot 6, d f=2, p<0\right.\end{array}$ & $\begin{array}{l}82 \cdot 2 \\
17 \cdot 8\end{array}$ \\
\hline
\end{tabular}

Columns may not add up to $100 \%$ due to rounding; numbers in brackets represent one respondent only.

Table 8 Overall and individual component scores on the NHP for each Rosser disability and distress category*

\begin{tabular}{|c|c|c|c|c|c|c|c|}
\hline \multirow[t]{2}{*}{ Rosser category } & \multirow[t]{2}{*}{ No of respondents } & \multicolumn{6}{|c|}{ NHP category: mean score } \\
\hline & & $P M$ & $P A$ & $S$ & $E$ & $S I$ & $E R$ \\
\hline $\begin{array}{l}\text { Disability: } \\
\text { I } \\
\text { II } \\
\text { III } \\
\text { IV } \\
\text { V } \\
\text { VI }\end{array}$ & $\begin{array}{r}146 \\
19 \\
16 \\
5 \\
15 \\
1\end{array}$ & $\begin{array}{r}3 \cdot 6 \\
14 \cdot 0 \\
15 \cdot 2 \\
72 \cdot 3 \\
44 \cdot 7 \\
-\end{array}$ & $\begin{array}{r}4 \cdot 6 \\
21 \cdot 6 \\
24 \cdot 7 \\
89 \cdot 6 \\
48 \cdot 1 \\
-\end{array}$ & $\begin{array}{l}10 \cdot 0 \\
38 \cdot 0 \\
39 \cdot 6 \\
77 \cdot 9 \\
52 \cdot 9 \\
-\end{array}$ & $\begin{array}{l}12 \cdot 9 \\
27 \cdot 8 \\
55 \cdot 9 \\
61 \cdot 3 \\
68 \cdot 1 \\
-\end{array}$ & $\begin{array}{r}5 \cdot 3 \\
7 \cdot 7 \\
18 \cdot 7 \\
29 \cdot 5 \\
25 \cdot 0 \\
-\end{array}$ & $\begin{array}{r}8 \cdot 5 \\
23 \cdot 4 \\
33 \cdot 4 \\
33 \cdot 0 \\
38 \cdot 6 \\
-\end{array}$ \\
\hline $\begin{array}{l}\text { Distress: } \\
\text { A (none) } \\
\text { B (mild) } \\
\text { C (moderate) } \\
\text { D (severe) }\end{array}$ & $\begin{array}{r}105 \\
39 \\
33 \\
17\end{array}$ & $\begin{array}{r}3 \cdot 7 \\
6 \cdot 1 \\
18 \cdot 0 \\
44 \cdot 8\end{array}$ & $\begin{array}{r}4 \cdot 8 \\
7 \cdot 3 \\
29 \cdot 6 \\
53 \cdot 3\end{array}$ & $\begin{array}{l}10 \cdot 5 \\
16 \cdot 8 \\
36 \cdot 4 \\
55 \cdot 6\end{array}$ & $\begin{array}{l}12.6 \\
17.0 \\
41.8 \\
59.6\end{array}$ & $\begin{array}{r}3.4 \\
6.5 \\
17 \cdot 7 \\
31 \cdot 6\end{array}$ & $\begin{array}{r}4 \cdot 7 \\
13 \cdot 2 \\
33 \cdot 2 \\
48 \cdot 2\end{array}$ \\
\hline
\end{tabular}

$\mathrm{PM}=$ physical mobility; $\mathrm{PA}=$ pain; $\mathrm{S}=$ sleep; $\mathrm{E}=$ energy; $\mathrm{I}=$ social isolation; $\mathrm{ER}=$ emotional reactions.

* Data on disability incomplete for five respondents; data on distress incomplete for 13 respondents. $(\mathrm{p}<0.001)$, and it is in the expected direction, with GHQ scores rising as Rosser scores decrease.

Since the GHQ was developed to assess psychiatric disturbance, it was hypothesised that some of the individual "feelings" items of the HMQ would show a positive relationship with the overall GHQ score. Ten of the 16 "feelings" items showed a significant correlation with GHQ score. Anxiety (Spearman's rank correlation coefficient 0.53 ), worry about the future (0.49), and sadness/depression $(0.47)$ had the highest correlation (all being significant at the 0.001 level). Of the eleven "feelings" items used in the algorithm to determine the level of distress in the HMQ, seven had a significant correlation with the overall GHQ score. The remaining four items were those which had the fewest patients reporting any problems (embarrassment, guilt, dependence on others or on a machine).

Table 7 shows how respondents in a "not healthy" state of health are distributed according to the Rosser categories and GHQ scores. More of this "not healthy" group are in Rosser disability states II or lower and in Rosser distress states $C$ and $D$. The percentages for disability level IV seem anomalous: this may be because of the small number of respondents in levels IV and V, but may also suggest that the description for level $\mathrm{V}$ (unable to work) is not clearly distinguished from level IV ("work ... seriously limited"), and respondents tend to categorise themselves as $\mathrm{V}$ rather than IV. Nearly $98 \%$ of "healthy" respondents scored below the GHQ threshold. Whereas only $2 \%$ of this group was classed above the threshold, the proportion in the "not healthy" group was nearly nine times higher.

\section{CONVERGENT VALIDITY: COMPARISON OF} DERIVED ROSSER CATEGORIES AND NHP

Respondents in the community reported most problems on the NHP dimensions of energy and sleep (mean scores 24 and 21 respectively). Fewer problems were reported for the dimensions of emotional reaction (15), pain (14), physical mobility (11), and social isolation (9).

From table 8 it can be seen that the mean scores for the individual NHP components increase as the Rosser disability and distress categories worsen. Once again, the scores for disability level IV and V seem to be anomalous. Pearson's correlations between the NHP components and Rosser score were all significant ( $p<0.001$, two-tailed), and in the expected direction. The highest correlation coefficient was between the Rosser score and physical mobility $(r=0.62)$, followed by pain $(r=0.52)$, sleep $(r=0.44)$, energy $(r=0.41)$, emotional reaction $(r=0.37)$, and social isolation $(r=0 \cdot 23)$.

One difficulty which arises when using the NHP in a community survey is that the most common answer to a question is "no", signifying no problem with that particular item. Nearly $60 \%$ of respondents in this study indicated that they had no problems with any of the 38 items on the NHP. When these respon- 
Table 9 Distribution of NHP scores in two subgroups*

\begin{tabular}{llc}
\hline NHP score & $\begin{array}{c}\text { "Healthy" } \\
(n=280)(\%)\end{array}$ & $\begin{array}{c}\text { Not healthy" } \\
(n=106)(\%)\end{array}$ \\
\hline 0 & $66 \cdot 4$ & $50 \cdot 0$ \\
$1-2$ & $16 \cdot 1$ & $5 \cdot 7$ \\
$3-11$ & $14 \cdot 3$ & 18.9 \\
$12+$ & $3 \cdot 2$ & $25 \cdot 5$ \\
& $\left(\mathrm{x}^{2}=51 \cdot 5, \mathrm{df}=3, \mathrm{p}<0.001\right)$ \\
\hline
\end{tabular}

*Data missing for three "healthy" respondents and one "not healthy" respondent.

dents were omitted from the analysis, however, and although the mean scores change, the same pattern of significant correlations persists.

Table 9 shows the distribution of NHP scores in the "healthy" and "not healthy" subgroups. As noted earlier, the modal response is zero, with over $65 \%$ of "healthy" respondents not answering positively to any of the items in the NHP questionnaire. Fifty per cent of the "not healthy" group also indicated no problems on the NHP; however, $25 \%$ of this group scored 12 or over, indicating a problem on a third of the NHP items. The distribution of scores for the two groups differed significantly.

\section{Discussion}

The HMQ was designed as a means of obtaining information capable of being processed to yield Rosser disability/distress categories. The performance of the HMQ has been judged against the NHP and GHQ to assess its validity as a measure of health status (assuming that both these measures are themselves "valid" measures). The results provide strong evidence of convergent validity. At the descriptive level, Rosser distress categories derived from the HMQ seem to correlate well with the GHQ. When the Rosser valuations are substituted for the derived categories there is a strong association between these scores and those produced by the NHP. All three measures discriminate between the "healthy" and "not healthy" subgroups of respondents.

As would be expected, several of the individual "feelings" items show significant correlation with the overall GHQ score, in particular anxiety and depression. The item "dependence on others" was not one of these, but this is probably due to the small number of respondents within the general community sample who were relying on others, for example, for help with self care, shopping, etc. The modal response to all NHP items was zero and this emphasises the importance of ensuring a large sample size in a study of the general community where major impairment is unlikely.

It is interesting to note that the NHP results from this study are similar to those from another study in which the NHP was completed by a control group selected randomly from the age-sex register of a large UK group practice, ${ }^{21}$ which found that again sleep and energy are the most common problems.

Similarly, for many of the NHP items in the "sleep" and "social interaction" dimensions, the incidence of positive responses for this study population were virtually identical to the responses from 1598 adults who completed the NHP as part of a community survey conducted in the York area. ${ }^{28} \mathrm{Within}$ the four other NHP dimensions, the Wolverhampton study population had a greater incidence of positive responses than the York population to all items except for "I lose my temper easily these days". This suggests that as a group they were experiencing poorer health, particularly in terms of energy/sleep (as shown by the higher percentage responding to the items "wake early", "feel tired all the time", "pain at night", "forgotten what it's like to enjoy myself", "everything is an effort", "in pain up and down stairs"). The respondents in this study may be a self selected group, possibly reflecting a tendency for people in poor health to want to take part in an interview about health. Ideally, we should also have collected data from those who refused to take part in the study to test for a significant response bias.

The HMQ has performed as well as the GHQ and NHP in discriminating between groups with different current experience of health, and has been useful for identifying the subgroup of the general population that is in poor health, or that scores highly on a psychiatric illness scale. There is considerable morbidity within the community ( $45 \%$ of respondents reported long standing illness, and one third were on regular medication), as well as identifiable risk factors for future disease $(30 \%$ were smokers and $42 \%$ were overweight). Although these figures are self reported, they tally with results from surveys such as the General Household Survey. These data reinforce the need for continued measurement of health status within the general population, with the dual aim of identifying areas of need, and then monitoring improvement as services are adjusted to meet that need. Health status measures such as the HMQ offer the prospect of such measurement.

In seeking to validate the HMQ against some alternative standard measure, we faced the recurring problem of identifying the elusive "gold standard". There is no one instrument which stands out above the rest, that unambiguously measures (health-related) "quality of life", and thereby provides the definitive reference against which all other instruments can be assessed. Even comparing the HMQ against two recognised and well used measures of outcome has its difficulties. The GHQ was originally designed as a screening test to detect psychiatric disorders, and thus focuses on psychological components of ill health. The NHP, while intended as a population survey tool, covers the dimensions of health in more detail, but was designed as a profile measure, without combining dimensions to produce an overall figure for health status. Neither instrument is therefore strictly comparable with the HMQ (or the Rosser classification). Examples that are more similar, such as the Sickness Impact Profile ${ }^{10}$ or the Quality of Well-Being Scale, ${ }^{29}$ have not been designed for postal use, and were developed outside the UK. Experiences of using the 
SF $36^{30}$ in a British setting are only at an early stage. The HMQ has its own strengths and weaknesses, but it may be considered useful as a general measure of health status to be used alongside other such measures.

Overall, we conclude that the HMQ is a viable, valid measure of self reported health status, and is suitable for use in the general population and may also be useful for investigating specific patient groups. We would like to thank Dr Roy Carr-Hill for collecting the
HMQ data as part of his Wolverhampton survey and for HMQ data as part of his Wolverhan
providing access to the full data set.

At the time of this study the authors were financially supported by grants from the Economic and Social Research Council and the Department of Health.

1 Fallowfield L. The quality of life: the missing measurement. London: Souvenir Press Ltd, 1990

Spilker B. Quality of life bibliography and indexes. Med Spilker B. Quality of life bibliograph
Care 1990;28(Suppl 12):DS1-77.

3 Teeling Smith G, ed. Measuring health: a practical ap-

proach. Chichester: $\mathrm{J}$ Wiley, 1988 .
$4 \mathrm{Kind} \mathrm{P}$. The design and construction of quality of life measures. York: Centre for Health Economics, University of York, 1988. Discussion paper no 43

5 Patrick D, Deyo R. Generic and disease-specific measures in assessing health status and quality of life. Med Car 1989;27(Suppl 3):S217-32.

6 Office of Population Censuses and Surveys. Morbidity stat istics from general practice: 3rd national study 1981-2. London: HMSO, 1989.

7 Martin J, Meltzer H, Elliot D. The prevalence of disability among adults. London: HMSO, 1988. OPCS Surveys of Disability in Great Britain.

8 Blaxter M. Health and lifestyles. London: Routledge, 1990.

9 Hunt S, McKenna SP, McEwen J, Williams J, Papp E. The Nottingham health profile: subjective health status and medical consultations. Soc Sci Med 1981;15:A221-9.

10 Bergner M, Bobbitt R, Carter WB, Gilson BS. The sickness impact profile: development and final revision of a health status measure. Med Care 1981;19(8):787-805.

11 Rosser R, Kind P. A scale of valuations of states of illness: is there a social consensus? Int $f$ Epidemiol 1978;7:347-58. 12 Euroqol Group. Euroqol ${ }^{c}$ - a new facility for the measure- ment of health-related quality of life. Health Policy 1990;16:199-208.

13 Williams AH. Economics of coronary artery bypass grafting. $B M F$ 1985;291:326-9.

14 Gudex C $Q A L Y s$ and their use by the health service. York: Centre for Health Economics, University of York, 1986. Discussion paper no 20.

15 Gudex C Kind P. The OALY toolkit. York: Centre for Health Economics, University of York, 1988. Discussion paper no 38 .

16 Guyatt G, Patrick D, Feeny D. Glossary. Controlled Clin Guyatt G, Patrick D, Feen

17 Carr-Hill R, McIver S, Humphreys K. Wolverhampton: a picture of health? York: Centre for Health Economics, University of York, 1987.

18 Goldberg DP. The detection of psychiatric illness by questionnaire. Oxford: Oxford University Press, 1972.

19 Hunt SM, McEwen J. The development of a subjective health indicator. Sociology of Health and Illness 1980;2:231-46.

20 Caine N, Sharples LD, English TAH, Wallwork J. Prospective study comparing quality of life before and after heart transplantation. Transplant Proc 1990;22:1437-9.

21 Ebrahim S, Barer D, Nouri F. Use of the Nottingham health profile with patients after a stroke. $\mathcal{F}$ Epidemio Community Health 1986;40:166-9.

22 Welburn P, Walker S. Assessment of quality of life in Parkinson's disease. In: Teeling-Smith G, ed. Measuring health: a practical approach. Chichester: J Wiley, 1988.

23 Wiklund I, Romanus B. A comparison of quality of life before and after arthroplasty in patients who had arthrosis of the hip joint. F Bone foint Surg $(A m)$ 1991;73A:765-9.

24 Kind P, Rosser R, Williams A. Valuation of quality of life: Kind $P$, Rosser R, Williams A. Valuation of quality of life
some psychometric evidence. In: Jones-Lee MW, ed. Th value of life and safety. Geneva: North-Holland, 1982.

$25 \mathrm{Kind} \mathrm{P}$, Gudex $\mathrm{C}$. The HMQ: measuring health status in the community. York: Centre for Health Economics, University of York, 1991. Discussion paper no 93.

26 Office of Population Censuses and Surveys. General House hold Survey. London: HMSO, 1984. OPCS Series, GHS no 14.

27 Government Statistical Service. Census 1981 : economic activity in Great Britain. London: HMSO, 1984.

28 Kind P, Carr-Hill R. The Nottingham health profile: a useful tool for epidemiologists? Soc Sci Med 1987;25(8):905-10.

29 Patrick DL, Bush JW, Chen MM. Methods of measuring levels of well-being for a health status index. Health Serv Res 1973;8:228-45.

30 Ware JE, Sherbourne CD. The SF-36 health status survey. 1. Conceptual framework and item selection. Med Care 1992;30(6):473-83. 